\title{
O murmúrio do tangível - A semântica tátil na sintaxe da superfície
}

\author{
SUSANA MARIA PIRES
}




\section{- RESUMO}

Poder-se-ia descrever a perceção tátil como a experiência de presença sem representação. Esta afirmação implicaria, no domínio das artes visuais, um discurso que, simultaneamente, afeta e se desvincula da problemática da ontologia da imagem e dos movimentos da linguagem. O sentido do tato é aquele que nos dá informação mais direta, real e concreta da superfície e corpo da matéria, no entanto a sua sintaxe é feita por relações abstratas. As qualidades e funções haptológicas dentro de cada cultura, o seu papel na comunicação e a forma como estas são afetadas pela tecnologia têm vindo a ganhar destaque nas criações artísticas contemporâneas, na academia e na sociedade em geral. Desdobrando o léxico do tato em sentido temático e função operativa, este artigo realiza uma breve trajetória ancorada na poética do tato no contexto das artes visuais. Paralelamente, indaga acerca da reciprocidade produtiva entre um pensamento centrado na funcionalidade tátil e o desenvolvimento de materiais interativos.

\section{PALAVRAS-CAVE}

Tato, tangível, superfície, contato, smart textiles.

\section{ABSTRACT}

Tactile perception could be described as the experience of presence without representation. This point may not have a good framework in the issues of the image and language. The sense of touch is which gives us the truest information of real surfaces, still its syntax is made by abstract relations. The basic quality or function of touch within culture, the role of touch in communication and the ways in which touch is affected by technology are in our days an expanding field of research. Distinguishing touch between thematic sense and operating function, this paper makes a brief trajectory anchored in the poetics of touch in visual arts. Will be investigated simultaneously the relation between the touch thought and the smart textiles.

\section{- KEYWORDS}

Touch, tangible, surface, contact, smart textiles.

\section{Introdução}

A plasticidade da superfície mantém uma relação íntima com a fisicalidade tátil e com o olhar háptico. Na proximidade real entre dois corpos ou entre um corpo e uma outra qualquer materialidade desenha-se uma troca invisível, uma permuta micro sensível nem sempre codificável. 
O tato opera através do tempo, percorrendo frações de superfície a cada instante. No contato entre dois limites tangíveis coabitam os princípios da física e o tempo da poesia. É por isso que o murmúrio do tangível ainda guarda segredos.

Pragmaticamente, sabemos que textura é a qualidade mais tangível dos objetos, sendo também a mais suscetível de mutações.

O rugoso e o liso, o frio e o quente, o mole e o duro, são elementos facilmente identificáveis e que surgem assiduamente no caracterizar da matéria. Mas nem sempre é fácil descrever uma experiência tátil. Hesitamos entre palavras possíveis e algo permanece indizível. Será porque o sentido do tato não exerce para com a linguagem uma contaminação fluente como acontece com a visão?

A omnipresença de metáforas visuais em toda a linguagem, bem como práticas sociais e culturais que podem variar de cultura para cultura de época para época vinculadas ao ocularcentrismo é a premissa inicial da obra de Martin Jay "Downcast Eyes - The Denigration of Vision in Twentieth-Century French Thought" (1994). Jay faz um mapeamento da história do pensamento ligada à organização social e à cultura, através de autores que elaboram considerações que se posicionam como divergentes face à hegemonia da visão.

Constance Classen, investigadora do Centre for Sensory Studies da Concordia University, especialista em história dos sentidos, afirma que vivemos numa sociedade da imagem em que há multiplas representações do tato, mas muito pouco para sentir. Segundo ela, o contínuo apelo ao sentido do tato que encontramos no imaginário contemporâneo tornou o tato o mais faminto dos sentidos.

Não se pretende aqui estimular uma disputa entre o regime ocular e o háptico, mas sim, pontuar a necessidade crescente de uma múltipla revalorização haptologica na sociedade líquida (Bauman, 2007) em que vivemos.

Byung-Chul Han (2016) afirma-nos que, hoje, o liso, o polido e a ausência de vincos são identificados como belo porque não oferecem resistência, nem nos causam incomodo ou dor. Em "The Book of Touch" (2005), Classen problematiza a inabilidade que dominou o sentido do tato durante décadas, considerando que seja talvez essa a explicação para a prática contemporânea de viver em casulos, para a criação de microcosmos fechados e seguros.

Por outro lado podemos encontrar um pensamento mais apaziguado com o futuro, nos textos escritos de Michel Serres. As obras iniciais do filósofo fazem uma apologia dos sentidos face á tirania da linguagem e dos sinais. Sabemos que, progressivamente, este autor foi integrando a valorização da tecnologia, orientada por Hermes o deus mensageiro, articulando com esta uma relação construtiva. $O$ seu pensamento assenta numa epistemologia de fluídos. Serres defende a importância das interconexões, das membranas, das passagens, dos cruzamentos e dos entrelaçamentos. Nada é estanque. Segundo ele, o mundo da comunicação é o mundo do toque e não da visão. A fluidez trouxe um toque generalizado e o mundo tornou-se tangível.

A canadiana Thecla Schiphorst (artista visual, webdesigner e coreógrafa) tem desenvolvido uma investigação referenciável sobre as relações entre o corpo e a tecnologia nas artes visuais e introduz-nos o conceito da palpabilidade do invisível. No texto "Body Matters: The Palpability of Invisible Computing" (2009) defende que a era da computação invisível não é definida meramente pela miniaturização tecnológica, uma vez que traz consigo uma mudança, criativa e cognitiva, do visível 
para o reino multi-sensorial do invisível. A metáfora da palpabilidade dimensiona-nos necessidade de articular uma incorporação física do ainda invisível. A palpabilidade é definida como uma intensidade que é percetível e que pode ser sentida.

Fomentamos uma tendência em acreditar que o tato e o toque resistem à virtualização. Mas é certo que hoje tecnologia a somastesia entrelaçam-se cada vez mais.

A permeabilidade entre a experiência técnica e a experiência sensível é um núcleo profícuo para reflexões criativas acerca do sistema vigente de conectividade generalizada.

Poderemos afirmar que a psicofísica do tato é relevante na conceção novas materialidades, nomeadamente os smart textiles?

E o que é afinal uma figura tátil? A complexidade de uma resposta a esta pergunta prende-se com a dificuldade de definir o próprio tato.

$\mathrm{Na}$ ferocidade veloz em que recebemos e trocamos informação hoje e, face aos hiper estímulos a que estamos expostos, o murmúrio do tangível exige um enclave no tempo.

\section{Teoria da pele}

Na história da pintura a relação com os sentidos surge por oposição ao sagrado e ao divino. Neste campo as cinco pinturas alegóricas resultantes da colaboração entre Jan Brueghel o Velho e Pieter Paul Rubens (1617/1618), são uma referência matriz que influenciou frutiferamente gerações posteriores. Na alegoria do Tato estão representadas diferentes sensações: picada do escorpião, a carícia de um beijo, a suavidade da pele, a volúpia dos panejamentos e o frio metálico das armaduras, a composição transmite concomitantemente dor e prazer.

Se as manifestações do corpo permaneceram veladas durante séculos, as últimas décadas são ricas em manifestações artísticas que exploram esta dicotomia (dor/prazer) até à exaustão.

Mas o que é pensar o tato? Tocar implica sempre alcançar o limite de algo. Implica a existência e a consciência do nosso próprio limite. Talvez por isso, um pensamento do toque deva passar por uma teoria da pele.

A pele é a principal interface do tato. Na experiência tátil interpessoal existe um conhecimento que se diferencia dos outros sentidos: o conhecimento de ambas as partes - a que toca e a que é tocada, com a particularidade de poder tocar-se tocando.

Atribuindo alguma prioridade ao tato Michel Serres ("Os cinco sentidos", 1985) encontra na pele o lugar de um sentido comum generalizado, o loco da mistura percetiva, um meta-sentido. A pele é onde a alma e o mundo se misturam.

$E$ a pele que se vê é diferente da pele que se toca?

Aristoteles deixou-nos como herança o tato como aporia. A história dos sentidos é marcada por uma incapacidade de localizar o sentido tátil, tornando-o geralmente um elemento motriz dos seus companheiros percetivos.

Os olhos também tocam. E é o próprio Serres que afirma que a pintura de Pierre Bonnard não é tão atraente para o olhar como para o tato. Atribui ao pintor a capacidade de nos fazer tocar a pele das coisas.

A poética da pintura sempre nos entrelaçou nesta exposição de presenças. 
Uma tateabilidade tácita.

Esboça-se aqui o indagar de uma desterretorização do sentido dominante da pintura (a visão) por uma afinidade com o tátil, em consonância com a voz de outros autores que ,pontualmente, vão abordando a questão.

Em "Francis Bacon: Lógica da sensação", obra escrita que o filósofo francês Gilles

Deleuze dedicou à pintura de Francis Bacon, o autor descreve o termo hifenizado Imagem-Sensação como a coincidência e identidade profunda entre imagem e sensação quando o que está em causa é a pintura.

Através deste texto de Deleuze podemos reconhecer que a captura de forças aparta-se da presença narrativa e do figurativo. Tornar visível o invisível, audível o inaudível e mesmo decifrar o indecifrável é sempre e antes de tudo uma questão do Tato, uma experiência e uma atividade que se experimenta com o corpo.

\section{Tateabilidade}

No texto "On touching" (2005), Jacques Derrida homenageia o pensamento de Jean-Luc Nancy conduzindo uma quase antologia da filosofia do sentido do tato, inaugurando as suas questões sobre as relações de proximidade, com a seguinte questão: Quando os nossos olhos se tocam, será dia ou será noite?

Quando o tato e a visão são um só sentido, o corpo existe como presente, relembrando a presença do outro numa relação sensorial ignorada no quotidiano.

Em cada experiência há um corpo ocupado por outro corpo. Há um corpo que é abrigado/confortado por outro. Ambos os corpos, aglutinados, são a solução dum espaço topológico, um espaço-estrutura relacional, onde imperam noções de convergência, continuidade e naturalmente de memória.

Derrida lembra-nos que é preciso antes de tudo falar de reflexividade, já que o contato não se submete ao paradigma da visão. Encontra aqui a transcendência ontológica do háptico: ver é tocar.

Quando duas se mãos tocam, há uma sensualidade da carne, uma troca de calor, um sentimento de pressão, de presença, uma proximidade da alteridade mesmo quando são as nossas próprias mãos que se tocam. Nesta dobragem, nesta dança dos limites de si para si e/ou de si com ou outro, própria de uma vontade mas desprovida de finalidade, que Ponty e Levinas tão bem descreveram, ouve-se o murmúrio, o murmúrio do tangível.

Tatear a dinâmica fluida dos limites da imagem corporal como ação operativa e poética é uma premissa dominante da obra de Lygia Clark.

Ícone incontornável do seu trabalho "Dialogo de Mãos" (1966) dá a acontecer o jogo da reflexividade tátil. O objecto-ponte inaugura a relação espacial entre dois intervenientes. Uma fita de moebius elástica ata os pulsos dos participantes que dialogam com movimentos das mãos. Em cada gesto é criada uma arquitetura biológica viva que finda quando a experiência acaba. A relação entre dois é usada como estrutura que, por sua vez, aciona uma proposta de conhecimento mútuo. Uma mão procura outra mão, toca, foge, envolve, dança. Duas mãos descobremse, envolvem-se ou evitam tocar-se. Toca-se o tato. Cria-se a experiência do diálogo entre dois participantes que partilham um terreno comum. Do espaço entre ambos surgiu um novo lugar, uma poética projetada a dois. O toque desdobra-se em em sentido temático e função operativa. 
Mergulhar nas preposições táteis de Lygia Clark ultrapassa a questão da participação que convoca a experiência corporal como condição da obra. Através dos seus objetos o espectador descobre o seu próprio corpo através das sensações táteis. Em obras como "Pedra e Ar" (1966) a artista oferece-nos o material como meio expressivo. A textura, o peso, a temperatura, o som e o movimento fazem-nos perceber as propriedades abstratas da matéria e simultaneamente aferir novos conhecimentos sobre o aparelho orgânico que habitamos na sua relação com a transitoriedade do existente. Lygia Clark faz-nos ouvir o murmurar do tangível para que possamos equacionar o intangível.

A mensagem murmurada da matéria ouve-se, também, nos esculturas da sua contemporânea Eva Hesse. Não é necessário tocar efetivamente nos seus objetos para estabelecer com eles uma relação tátil. Estes são a matéria com a potência da memória de um corpo. Não são apenas os seres viventes que memorizam a matéria, esta mantém em si a memória das suas condições de possibilidades. (Figura 1).

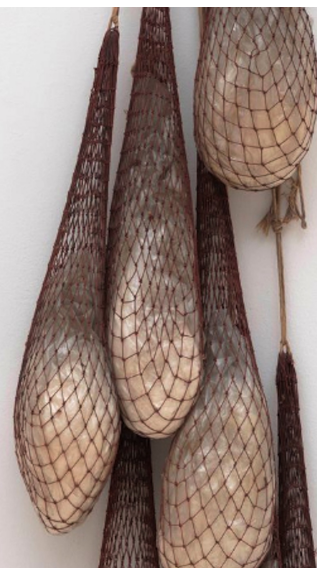

Figura 1. Eva Hesse, Untitled or Not Yet, rede, polietileno, papel, pesos de chumbo e corda, $180 \mathrm{~cm} \times 39 \mathrm{~cm} \times 20 \mathrm{~cm}, 1966$ - Coleção SFMOMA (San Francisco Museum of Modern Art). Fotografia -The Estate of Eva Hesse.

E em que se pensa quando nos deixamos envolver pelas estruturas orgânicas de Ernesto Neto? Em tudo e em nada. Os seus invólucros marcados pela simplicidade formal e a clareza cromática, constroem lugares silenciosos visualmente. Tateamos com o corpo e com os olhos o material em tensão das suas membranas, peles e contra-peles. Olhamos, cheiramos, tocamos, ouvimos sem referências à realidade concreta, mas tudo nos é familiar.

Assistimos às dialéticas incontornáveis do dentro e do fora, do peso e leveza, transparência e opacidade, movimento e serenidade ... e sabemos que, ali, o tangível murmura ao ouvido do intangível.

Poderá afirmar-se que a sua obra expõe as potencialidades do espaço intermédio como um loco de permanente descoberta das relações entre o espaço e os corpos, entre o corpo e os corpos, entre o corpo e o orgânico do não orgânico.

A canadiana Thecla Schiphorst (artista visual, web designer e coreografa) tem desenvolvido uma investigação referenciável acerca das relações entre o corpo e a tecnologia nas artes visuais. 
O seu trabalho questiona a forma como a tecnologia medeia a representação e a experiência do corpo, integrando modelos de representação cientifica na experiência corporal.

Usa como ponto de partida uma subversão da relação visual objetiva através de uma experiência baseada no conhecimento percetivo: ouvindo através do toque, vendo através da audição.

O seu objetivo é tornar visível a comunicação não verbal (invisível), que ocorre dentro de nós ao estabelecemos relações de proximidade com outros corpos. Para tal cria sistemas que respondem ao estado fisiológico dos participantes no espaço.

"Bodymaps: artifacts of touch" (1995-96) e "Between bodies: wearables for the telepathically impaired" (2003-2004) são exemplos de duas obras em que Schiphorst usa a tecnologia para reivindicar o corpo como um sistema interativo, tanto metafórica como fisicamente. Os seus trabalhos são geralmente peças de roupas. A exploração da obra por quem a usa, induz a uma performatividade onde se vão descobrindo informações derivadas da fisiologia como gestos e outros mecanismos não verbais. Os seus objetos vestíveis aglutinam o material têxtil com sensores e microssistemas programáveis que permitem aumentar os modos verbais e visuais da comunicação. No âmbito da sua investigação Schiphorst desenvolveu uma série de workshops sob o título: The whisper workshop: modeling connection and extension. O objetivo desta ação coletiva centrava-se na exploração de conhecimento sobre a forma como as pessoas prestam atenção aos seus próprios estados corporais e como compartilham esses estados com os outros num determinado espaço. Os participantes eram convidados a ouvir o toque e o movimento, a visualizar as experiências corporais como a respiração, o batimento cardíaco e movimentos lentos do corpo, treinando a atenção e a consciência, processo que decorria focando a subtileza da somática com o intuito de a apreenderem cognitivamente e, posteriormente, virem a reproduzir criativamente tais experiências vividas, metaforizando as ações através de adereços, sensores, objetos e coreografias.

$\mathrm{Na}$ sequência desta pesquisa desenvolver um conjunto de objetos que denominou "Wearable body architectures" (2001-2003). São objetos que captam e reagem à ressonância do corpo, a estímulos exteriores. Resultaram em vestes para prestar atenção aos sussurros do mundo, a serem usadas como anexos ou prolongamentos do corpo. Schiphorst entende os sentidos como mecanismos de busca ativa para a compreensão informal do mundo. Defende que o papel da sinestesia e do movimento são inseparáveis da perceção, no seu discurso e obra, somática e tecnologia são uma ponte construtiva e em construção.

"Philosophy in the Flesh: The Embodied Mind and Its Challenge To Western Thought" (1999) é um livro escrito por George Lakoff e Mark Johnson que coloca em diálogo as investigações anteriores de ambos os autores, posicionando dentro das ciências cognitivas um outro entendimento sobre a somática na apreensão do conhecimento e da imaginação. Defendem que a mente é corporizada, que o pensamento é, em parte, inconsciente e que os conceitos abstratos são em parte metafóricos.

Segundo eles, o desempenho conceptual e os modos de questionamento face à realidade dependem dos sentidos, da forma como nos movemos e manipulamos os objetos. George Lakoff inicia esta investigação no seu livro "Metaphors We 
Live By “(2003), influenciado por Mark Johnson em "The Body in the Mind” (1987), empenha-se em defender que todo o pensamento tem origem na experiência corporal, ou seja, a apreensão da experiência da manipulação do mundo físico das superfícies, das distâncias, campos de força e movimentos estabelece as bases abstratas do pensamento. Os autores propõem o conceito de razão corporificada, referindo-se à formação de conceitos no e pelo corpo, nas trocas entre os seres humanos e o mundo, através da perceção multissensorial, da imaginação e do sistema motor na vivência diária. Este nível de compreensão possibilita a maximização do contacto com a realidade, conduzindo ao desenvolvimento da capacidade de projeção imagética, reconhecida como uma faculdade cognitiva vital. Revelam, assim, a estrutura metafórica subjacente a cada modo de pensamento, a fim de mostrarem como a metafísica de cada teoria flui a partir das suas metáforas.

A intraduzibilidade que se estabelece na relação tátil entre dois corpos e entre o corpo e a matéria é um espaço criativo que pode potenciar novas formas de estar e pensar. (Re)conectar os indivíduos com os seus próprios sentidos e explorar novas abordagens interativas, não devem ser posições antagónicas mas, sim, complementares.

Os novos interfaces multissensoriais que envolvem a tecnologia vão-nos permitindo, a cada dia, experienciar o antes impossível.

\section{Coordenadas do tangível}

Poderá afirmar-se que existem três tipos de toque: um toque ativo face às superfícies existentes, que explora a textura, a temperatura e a vibração; um toque passivo, que corresponde ao ser tocado; um toque de diálogo, numa sequência de tocar e ser tocado.

Os interfaces hápticos são, na atualidade, objetos em expansão. No entanto, a privação do toque real contínua a ser uma das mais significativas diferenças entre a comunicação à distância e a comunicação em co- presença.

Gregory Chatonsky, na sua instalação interativa "Se Toucher Toi" (2004), expõe as fronteiras entre corpo e interface, destituindo progressivamente a ilusão que é a imersão no universo tecnológico. A obra, composta por um receptor de movimento e uma projeção, convida o espectador a estabelecer um diálogo de mãos com um corpo desconhecido que habita o outro lado do interface. (Figura 2)

Num primeiro instante, o usuário percebe que ao mover a sua mão na superfície de vidro, a imagem desta aparece reproduzida na projeção, sobreposta à imagem de outra mão. Ao manipular o movimento, as duas mãos interagem entre si. Após alguns instantes deste jogo correspondido entre a imagem de duas mãos que comunicam simulando o toque, estas deixam de ter movimentos correspondentes, tocando-se em circuitos independentes dos gestos do usuário. Isto acontece porque, a determinado momento, é projetada uma imagem gravada de uma outra interação. Este desfasamento entre a corporalidade e os mecanismos tecnológicos constitui um ruído na estrutura da interação. Emerge então no usuário uma sensação de perda de controle e de incapacidade. Tal facto, vem a revelar o espaçamento entre os dois locais e a acionar a tomada de consciência do automatismo vigente no uso das ligações técnicas. Chatonsky apoia-se no conhecimento corporificado da experiência vivida para mostrar que, inicialmente, o nosso sentido da vi 


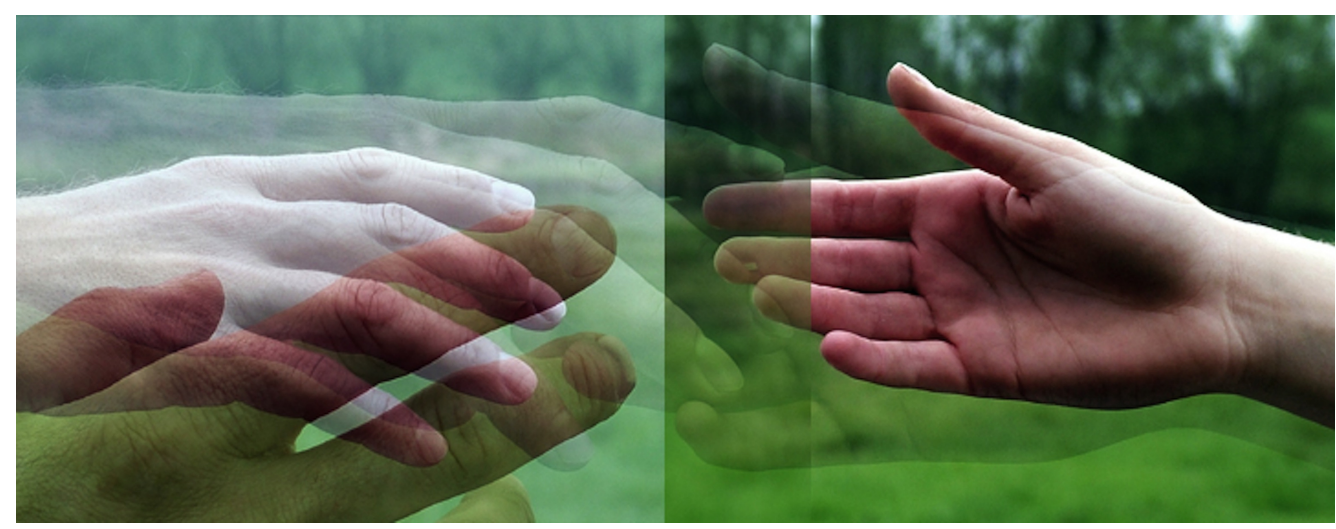

Figura 2. Gregory Chatonsky, Se Toucher Toi, computador, monitor, webcam, software personalizado. (Software -Vadim Bernard, Stéphane Sikora, produção - Le Fresnoy studio national des arts contemporains), 2004. Fotografia de Gregory Chatonsky.

são consegue iludir-nos através de uma perceção de experiência de toque, naquilo que é uma possibilidade da sua reprodução mas que essa ilusão é transitória.

A obra "Se Toucher Toi" comporta uma crítica à imersão tecnológica "Tele-

matic Dream" de Paul Sermon, concebida em 1992, era um convite sedutor a novas experiências físicas mediadas por dispositivos técnicos. "Telematic Dream" é uma proposta ancorada na noção abstrata de corpo virtual que, à data, pretendia explicitar a validade material da experiência humana mediada através de uma sobreposição de acontecimentos que se estruturavam pela representação do toque. Formalmente, esta instalação é composta por duas camas e vários monitores colocadas em locais distintos: um quarto sem iluminação e um outro com alguma luz. Só o segundo é acessível ao público. Ambas as divisões estão supervisionadas por câmaras de vídeo. A instalação é construída com o auxílio de uma rede digital de transmissão que viabiliza a ligação dos interfaces. A cama do quarto iluminado recebe a projeção da imagem captada no segundo espaço. Nesta segunda divisão, uma performer habita e dinamiza o espaço durante o período em que a obra está ativa. O público é convidado a subir à cama onde se encontra projetada a imagem da performer. Uma outra câmara capta a imagem da interação entre corpo real e a imagem projetada, ou seja, capta a imagem de dois corpos em diálogo. Por sua vez, essa imagem aparece nos monitores que ladeiam as camas. Este jogo de sobreposições procura desconstruir conceções pré-definidas das noções de relação entre corpos, de corpo representado e de corpos mediados. A máquina transforma o processo de comunicação na relação de um-para-o-outro num processo também de reversibilidade a partir do mesmo, dado que o usuário não interage apenas com o outro, mas também com a imagem do seu próprio corpo. Inclui assim referência a um auto-voyerismo. O trabalho explora a presença, a ausência da interação humana, no seio das comunicações mediadas pela tecnologia. $O$ usuário interage com o corpo ausente pela simulação do toque. Mesmo consciente de que está envolto por uma encenação técnica, a sua resposta performativa ao dispositivo instalativo é a de reprodução comportamental de uma experiência sensível de co-presença. No entanto, neste diálogo tateante não acontecem trocas de textura, temperatura ou vibração.

Em 1992 ano de concepção e apresentação de "Telematic Dream", Paul Sermon convidou Susan Kozel para desempenhar o papel de performer no quarto não iluminado da instalação. A participação neste projeto foi um marco no percurso 
da coreógrafa que tomou então esta experiência como objeto de reflexão.

Susan Kozel elaborou um estudo centrado na interação sensorial dos corpos entre si e na relação do corpo com os interfaces digitais. "Closer" (2007), o resultado escrito de uma pesquisa de vários anos, trouxe para o contexto académico a experiência sensível, vivida, mediada pela tecnologia. Kozel transpõe a permeabilidade entre experiência sensível e técnica, defendendo que a relação com os sistemas tecnológicos requer a exploração de uma nova gama de experiências físicas que proporcionam uma expansão da perceção e da consciência corporal. O seu discurso é uma proposta que resulta no atenuar das dualidades: humano/computador; material/imaterial; analógico/digital; orgânico/inorgânico; corpo/mente.

Parte dos conceitos de inter-subjectividade e alteridade e vai, ao longo dos capítulos, desenvolvendo uma crítica à noção idealista de telepresença e à interação online, fornecendo uma explicação materialista de espaço e de virtualidade.

O seu foco de estudo é a realidade física da conectividade humana estruturada a partir do conceito "carne", de Merleau Ponty. O produto do seu trabalho são performances que refletem o corpo na imersão social e com objectos vestíveis programados por sistemas digitais. Estes trabalhos propõem uma experimentação sensorial de contacto com o nosso próprio corpo, com o corpo de outros e de reação a estímulos provocados por sistemas tecnológico.

Defendendo e argumentando a pertinência da fenomenologia como modo de integrar o intelecto com a experiência sensorial, afirma o corpo como base do conhecimento e da experiência. O seu trabalho marca e reflete a inscrição corpórea cuja origem é uma trama ontológica no âmbito atual da experiência.

Segundo ela, os fenómenos de reverberação, ressonância e repercussão inerentes à receção fenomenológica da informação, não desaparecem quando se expõem por via de uma interface. Estas noções não são significativas em abstrato, mas o movimento e a corporalidade podem ser lidos através delas.

O que a sua tese pretende argumentar é que a perceção e a construção da individualidade e da alteridade emergem com a exposição do eu-corpo ao corpooutro. Amplia esta conceção, diferida a partir de Ponty, Levinas e Deleuze, para os corpos digitais e para a possibilidade de descobertas através da digitalização do próprio corpo. Defende que a relação quiásmica que temos com o mundo táctil e visual, a sua sobreposição e a sua desregularização, tem espaço para a fenomenologia de novas experiências intersubjetivas e que as práticas artísticas são um campo profícuo de exploração e integração de novos paradigmas multissensoriais.

A relação do tátil com o digital superou, há muito, os ecrã hápticos. Mas, poderá o tato ser virtualizado?

"Hardiman", a mão robótica de Ralph Mosher, pode ser considerada a percursora da tecnologia háptica que começou a ser desenvolvida no final dos anos 60. Tais conhecimentos foram progressivamente codificados pela ciência computacional que veio a agilizar ratos, joysticks e recetores articulados adaptáveis aos dedos dos utilizadores, bem como outros instrumentos que permitem atualmente uma interação quinestésica com a interface do computador. Estes sistemas fornecem um feedback que simula propriedades físicas da matéria, tais como o peso, o atrito e a textura.

O fruto do aperfeiçoamento destes sistemas é hoje aplicado com fins pedagógicos, nomeadamente em museus. 
Os artefactos do museu são reproduzidos digitalmente e o usuário pode explorar a topografia de um determinado objeto dentro de um ambiente digital.

A superação da rigidez do ecrã permite-nos entrar num campo em que a experiência digital aumenta qualitativamente.

"Firewall" (2013), é uma instalação interativa resultante do trabalho colaborativo entre Aaron Sherwood e Mike Allison. Nesta obra, uma película de elastano esticada atua como membrana sensível à profundidade. Ao ser tateada, empurrada ou acariciada, esta responde aos estímulos quinestésicos através de composições musicais e de uma imagem alterável de fogo em expansão. (Figura 3)

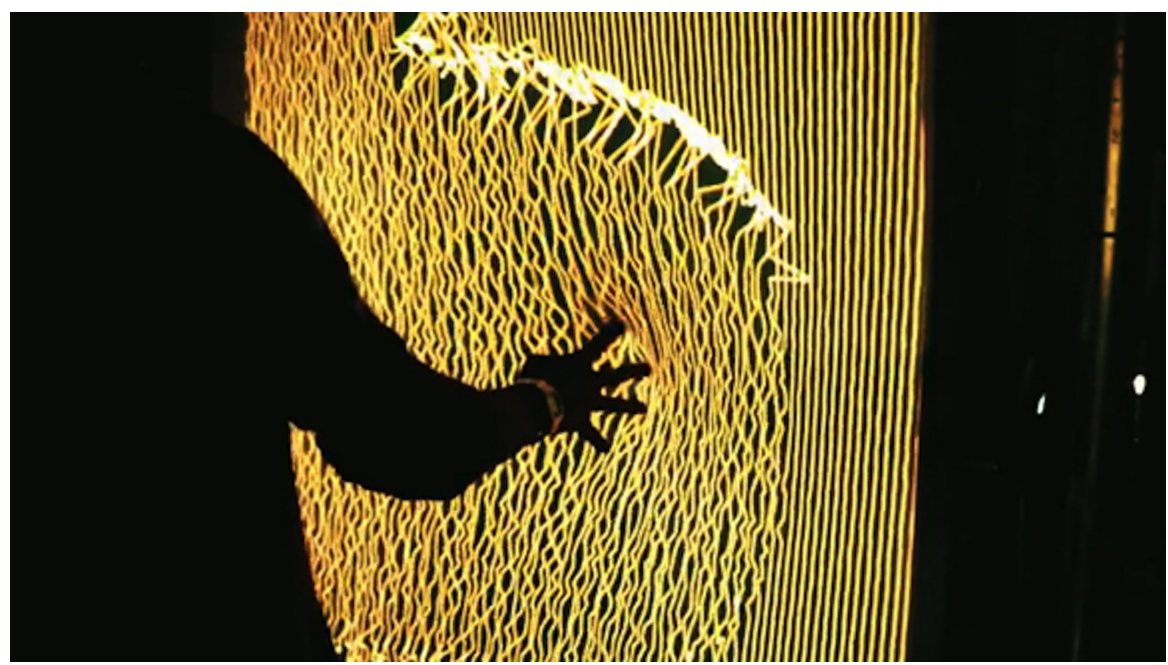

Figura 3. Aaron Sherwood e Mike Allison, Firewall, 2013, tela de elastano, projetor , 2.5D display, arduino e kinect, (software - processing ;Max/MSP) , 2013. Fotografia disponível em ( http://aaron-sherwood.com/works/firewall/).

Os têxteis são a matéria que estabelece uma maior relação de proximidade, proteção e conforto para com o corpo.

A qualificação material dos têxteis como interfaces multissensoriais que conectam o usuário com a sua perceção dos sentidos, produzindo experiências imersivas, é hoje um território em forte expansão. Aqui, aliam-se arte, design, ciência e indústria.

Os denominados Smart Textiles aglutinam a tecnologia digital e as fibras têxteis. A conceção de têxteis interativos possibilita a comunicação de novas formas expressivas através dos têxteis. Estes materiais híbridos permitem a alteração das suas estrutura, cor e temperatura de diversas formas, em resposta a estímulos ambientais.

A exposição "SmartTextiles Wearable Services" (Tilburg, 2015) divulgou as mais recentes colaborações entre design têxtil e tecnologia.

Podemos encontrar nos têxteis e na sua relação com dispositivos tecnológicos comportamentos de tensão, ressonância e reversibilidade sonora e tátil com o propósito de contribuir para um discurso que coloca em diálogo o conhecimento científico dos materiais e a sua plasticidade inerente.

Francesca Perona, designer e investigadora, tem aprofundado o estudo do potencial percetivo tátil através das relações dos têxteis com as tecnologias. O seu trabalho "Crafting Human Perception" (2012) foi apresentado no Victoria \& Albert Museum, integrando o "Digital Futures". Trata-se de uma escultura interativa que 
explora novas formas de entender a percepção humana. A obra repensa a relação tradicional entre corpos e superfícies têxteis artesanais, aumentando as funcionalidades comuns através de sensores.

Os painéis de tecido detectam as vibrações produzidas pelas nossas mãos enquanto os acariciam, apertam, movem, tocam ou arranham à superfície. Um circuito electrónico incorporado amplifica as vibrações hápticas em tempo real, reproduzindo-as através de efeitos sonoros.

Através destes processos, as superfícies têxteis estáticas evoluem para membranas interativas cujos motivos tridimensionais estimulam a exploração da perceção sensorial.

Esses artefatos têxteis podem ser considerados como entidades de natureza híbrida, objetos relacionais com potenciais interativo e transformador latentes. A experiência multi-sensorial resultante do uso de smart textiles pode criar uma dinâmica sensorial íntima entre os diversos sistemas perceptivos, proporcionando, uma cada vez mais afinada tomada de consciência da interação percetiva.

\section{Considerações finais}

E se o conforto tátil nos procura e nos encontra?

O cobertor robótico criado pelo artista canadiano Nicolas Stedman ("The Blanket Project", 2001) é capaz de navegar dentro de um espaço fechado indo ao encontro dos corpos presentes. Este objeto autómato aproxima-se, como que por magia, dos habitantes do espaço, proporcionando-lhes estimulações físicas conducentes a sensações de conforto.

O artefacto assombra e funciona através de ambos: técnica e desejo.

Existirá uma essência do tato, do toque? Quem toca o quê e quem?

A carícia, será sempre uma figura do tato. Mas é o indizível da essência do tátil que nos permite continuar a tatear novos caminhos de conciliação do corpo com o mundo.

Ouvir o murmúrio da matéria altera a linearidade do tempo. Num abraço tocamos o intangível da existência.

O tato reinventa-se nas aporias de Aristoteles, nas mãos de Rodin, nos nenúfares de Monet e expande-se nas metonímias de Nancy. Porque a essência do tátil, como diz Serres, é o enigma do unicórnio.

\section{Referências}

ACKERMAN, Diane (1998). Uma História Natural dos Sentidos. Lisboa: Temas e Debates, Actividades Editoriais.

BAUMAN, Zygmunt. Amor Líquido. Relógio’Água, Lisboa, 2006.

BERGSON, Henri. Matéria e Memória: Ensaio sobre a relação do corpo com o espirito. Martins Fontes, São Paulo, 1990.

CLASSEN, Constance (ed). The book of Touch. Bergpublishers, Nova lorque, 2005. 
DERRIDA, Jacques. On Touching : Jean-Luc Nancy ( trad. Christine Irizarry). Stanford University Press, California, 2005.

HAN, Byung-ChuL. A Salvação do Belo. Relógio de água editora, Lisboa, 2016.

JAY,Martin. Downcast Eyes - The denigration of vision in twentieth-century french tought. University of California Press, 1994.

JOHNSON, Mark; LAKOFF, George. Philosophy in the Flesh: The Embodied Mind and Its Challenge To Western Thought. Basic Books, New York, 1999.

JOHNSON, Mark Johnson. The Body in the Mind. The University of Chicago, Chicago, 1987.

KOZEL, Susana. Closer - performance, technologies, phenomenology. Massachusetts Institute of Technology. The Mit Press, Cambridge;Massachusetts; Londres, 2007.

LAKOFF, George. Metaphors We Live By. The University of Chicago, Chicago, 2003.

MERLEAU-PONTY, Maurice. A fenomenologia da percepção. Martins Fontes, São Paulo, 1994

MIGNONNEAU, L.; SOMMERER, C. (ed). Interface Cultures: Artistic Aspects of Interaction. Transaction Publishers. London, 2008.

MIRANDA, José A.B e CRUZ, M Teresa (org). Crítica das Ligações na Era da Técnica. Tropismos, Lisboa, 2002.

NANCY, Jean-Luc. Being Singular Plural. Stanford University Press ( Meridian - Crossing Aesthetics), California, 2000

SCHIPHORST, Thecla. Between Bodies: using Experience Modeling to Create Gestural Protocols for Physiological Data Transfer. in http://www.sfu.ca/ tschipho/whispers/CHI04BetweenBodiesFringe.pdf ( consultado 12.1.2015)

SCHIPHORST, Thecla. Body Matters: The Palpability of Invisible Computing. in Leonardo, Vol. 42, No. 3 (2009), (pp. 225-230, 209).

SIMÃO, Cristiana V. (1997). Mens Sana in corpore sano? Reflexões sobre o enigma do corpo. Philosophica 9 pp.207-223. Disponível em <http://www.centrodefilosofia.com/uploads/pdfs/philosophica/9/12.pdf>

SERRES, Michel. "The five senses. A philosophy of Mingled Bodies". Continuum International Publishing Group. Londres, 2008

SOBCHACK, Vivian (2004). Carnal Thougths. California: University of Califórnia Press.

Recebido em: 28/11/2016 - Aprovado em: 25/05/2017 